\title{
Simultaneous detection of lignans and tocopherols in sesame oil by reversed-phase high-performance liquid chromatography
}

\author{
Min Pang ${ }^{1}$, Lulu Cao ${ }^{1}$, Donglei Zheng ${ }^{1}$, Zheng Lei ${ }^{1}$, Yuanfei Ge ${ }^{1}$, Jieshun Cheng ${ }^{1}$, \\ Shaotong Jiang ${ }^{1}$, and Lili Cao ${ }^{1}$ \\ ${ }^{1}$ Hefei University of Technology
}

June 17, 2020

\begin{abstract}
A rapid and efficient method for the simultaneous detection of lignans (sesamol, sesamin, sesamolin) and tocopherols $(\alpha-$ tocopherol, $\gamma$-tocopherol, $\delta$-tocopherol) in sesame oil by reversed-phase high-performance liquid chromatography (RP-HPLC) has been established. The samples were ultrasonically extracted in methanol and eluted via a methanol-water gradient on a reversed-phase C18 column with UV/Vis detection. The recoveries of the six analytes ranged from $88.22 \%$ to $100.13 \%$, and the relative standard deviations ( $\mathrm{RSD}, \mathrm{n}=6$ ) ranged from $1.90 \%$ to $4.57 \%$. This method allowed for measurement of the concentrations of lignans and tocopherols in six commercial sesame oils. This technique is simple, accurate, and highly sensitive and can therefore be used for the routine analysis of real samples.
\end{abstract}

Simultaneous detection of lignans and tocopherols in sesame oil by reversed-phase highperformance liquid chromatography

Min Pang ${ }^{\mathrm{a}}$, Lulu Cao ${ }^{\mathrm{a}}$, Donglei Zheng ${ }^{\text {a b }}$, Zheng Lei ${ }^{\mathrm{a}}$, Yuanfei Ge ${ }^{\text {a b }}$, Jieshun Cheng ${ }^{\text {a b }}$, Shaotong Jiang $^{\mathrm{a}}{ }^{\mathrm{b}}$, Lili Cao ${ }^{\mathrm{a}} \mathrm{b}^{*}$

${ }^{a}$ School of Food Science and Bioengineering, Hefei University of Technology, Hefei, 230009, P. R. China

${ }^{b}$ Key Laboratory for Agricultural Products Processing of Anhui Province, Hefei, 230009, P. R. China

*Corresponding author:

Lili Cao, lilycao504@hfut.edu.cn

ABSTRACT: A rapid and efficient method for the simultaneous detection of lignans (sesamol, sesamin, sesamolin) and tocopherols ( $\alpha$-tocopherol, $\gamma$-tocopherol, $\delta$-tocopherol) in sesame oil by reversed-phase highperformance liquid chromatography (RP-HPLC) has been established. The samples were ultrasonically extracted in methanol and eluted via a methanol-water gradient on a reversed-phase C18 column with $\mathrm{UV} / \mathrm{Vis}$ detection. The recoveries of the six analytes ranged from $88.22 \%$ to $100.13 \%$, and the relative standard deviations (RSD, $\mathrm{n}=6$ ) ranged from $1.90 \%$ to $4.57 \%$. This method allowed for measurement of the concentrations of lignans and tocopherols in six commercial sesame oils. This technique is simple, accurate, and highly sensitive and can therefore be used for the routine analysis of real samples.

Keywords: Sesame oil; Lignans; Tocopherols; Reversed-phase high-performance liquid chromatography

\section{Introduction}

Sesame oil contains up to $80 \%$ unsaturated fatty acids (Wan et al., 2015), yet displays greater resistance to oxidation than other dietary vegetable oils. This enhanced oxidative stability stems from its rich content of endogenous antioxidants, such as lignans and tocopherols (Konsoula \& Liakopouloukyriakides, 2010; 
Mahendra Kumar \& Singh, 2015). Sesamin, sesamolin, and sesamol (Fig.1) are the main lignans in sesame oil and are reported to display a variety of important bioactivities, including anticancer activity (Yokota et al., 2007), anti-inflammatory activity (Yashaswini et al., 2016), and free radical scavenging (Suja et al., 2004). In addition, they reduce serum cholesterol levels and blood lipids (Hirata et al., 1996; Visavadiya \& Narasimhacharya, 2008), to enhance tocopherol antioxidant activity within lipid peroxidation systems (Ghafoorunissa et al., 2004), and to promote health generally by other physiological functions (Namiki \& Mitsuo, 1995). The primary tocopherols in sesame oil are $\alpha-, \gamma$-, and $\delta$-tocopherol (Fig.1; Williamson et al., 2008). Tocopherols are key antioxidants that inhibit carcinogenesis, mutagenesis, and cell transformation (Longnecker et al., 1992; Barve et al., 2009; Helzlsouer et al., 2018; Smolarek \& Nanjoo, 2011) and function in islet cell protection (Duggan et al., 2010), immune regulation (Morel et al., 2011), and the prevention of coronary heart disease (Pruthi et al., 2001).

In recent years, sesame oil has become popular because of its unique flavor, nutritional value, and pharmacological activities. As lignans and tocopherols play an important role in the bioactivities of sesame oil, it is of practical significance to determine their content. Methods for identifying and/or quantifying lignans and tocopherols in sesame oil include reversed-phase high-performance liquid chromatography (RP-HPLC) (Hemalatha \& Ghafoorunissa, 2004; Rangkadilok et al., 2010; Shi et al., 2017; Williamson et al., 2008; Wu, 2007; Xu et al., 2018), normal-phase high-performance liquid chromatography (NP-HPLC) (Ballus et al., 2014; Fernandes et al., 2015; Shi et al., 2018), thin-layer chromatography (TLC) (Kamal-Eldin et al., 1991; Utsunomiya, 2000), and gas chromatography (GC) (Kamal-Eldin et al., 1994; Li et al., 2002; Tashiro et al., 1990). Among these, the most commonly used method is HPLC. The content of lignans in sesame oil has been determined by RP-HPLC using methanol as the extraction solvent, while the content of tocopherols in sesame oil has been determined by NP-HPLC using $n$-hexane as the extraction solvent. However, there have been no reports in the literature for the simultaneous determination of these analytes in sesame oil. These repeated analysis processes make the detection of lignans and tocopherols in sesame oil a complicated task and are not suitable for routine analysis and batch processing. RP-HPLC is the most widely applied separation mode in liquid chromatography due to its high column efficiency, high resolution, good stability, and reproducibility of retention time. Therefore, RP-HPLC is the ideal platform on which to develop a method for achieving the simultaneous determination of lignans and tocopherols in sesame oil.

In this study, the extraction of lignans and tocopherols from sesame oil with methanol was optimized by ultrasound. The compounds were separated using an optimized RP-HPLC technique with UV-Vis detection. The pretreatment and analysis are simple and rapid and the results are accurate; therefore, this method is suitable for the routine analysis and quality control of lignans and tocopherols in sesame oil.

\section{Materials and methods}

\subsection{Materials and Chemicals}

The lignan standards, sesamin, sesamolin, and sesamol, were purchased from Sinopharm Medicine Holding Co., Ltd. (Shanghai, China). Tocopherol standards, $\alpha$-tocopherol, $\gamma$-tocopherol, and $\delta$-tocopherol, were obtained from Sigma-Aldrich (St Louis, MO, USA). Purities of each standard were [?] $98 \%$. HPLC grade methanol was obtained from Sinopharm Medicine Holding Co., Ltd. (Shanghai, China). Ultra-pure water for HPLC analysis was obtained from a Millipore Milli-Q system (Billerica, MA, USA). Six commercial sesame oils (including hot-pressed sesame oil, grinding sesame oil, and cold-pressed sesame oil) were purchased from retail markets in Anhui provinces, China. Sesame oil samples were assigned a unique number and stored at $-18{ }^{\circ} \mathrm{C}$ in the dark prior to analysis.

Stock solutions of the lignan and tocopherol standards were prepared in methanol $\left(650 \mu \mathrm{g} \mathrm{mL}^{-1}\right.$ for sesamin, $600 \mu \mathrm{g} \mathrm{mL} \mathrm{m}^{-1}$ for sesamolin, $500 \mu \mathrm{g} \mathrm{mL} \mathrm{m}^{-1}$ for sesamol, $200 \mu \mathrm{g} \mathrm{mL} \mathrm{m}^{-1}$ for $\alpha$-tocopherol, $300 \mu \mathrm{g} \mathrm{mL} \mathrm{m}^{-1}$ for $\gamma$ tocopherol, and $200 \mu \mathrm{g} \mathrm{mL} \mathrm{mL}^{-1}$ for $\delta$-tocopherol). Working standard solutions were prepared by diluting the stock solutions to the desired concentrations. All the standards were stored at $-18{ }^{\circ} \mathrm{C}$ in the dark.

\subsection{Sample Preparation Method}


Samples of sesame oils were accurately weighed $(1.0 \pm 0.01 \mathrm{~g})$ into a $10-\mathrm{mL}$ centrifuge tube and diluted with $3 \mathrm{~mL}$ HPLC-grade methanol. The mixture was vigorously shaken for $1 \mathrm{~min}$ with a vortex mixer and then sonicated in an ultrasound bath for 5 minutes. The mixture was centrifuged using a CR22G II Hitachi high-speed refrigerated centrifuge (Chengdu Shengke Instrument Co. Ltd, Chengdu, China) at $4000 \mathrm{rpm}$ for 3 min. The supernatant was transferred into a $10-\mathrm{mL}$ brown volumetric flask, and the extraction process was repeated twice using $3 \mathrm{~mL}$ of methanol for each extraction. All extracts were combined and the final volume of each extract solution was adjusted to $10 \mathrm{~mL}$ with methanol. The extracts were filtered through a $0.22-\mu \mathrm{m}$ nylon syringe filter (ANPEL Scientific Instrument Co. Ltd, Shanghai, China) and stored at $-18{ }^{\circ} \mathrm{C}$ prior to HPLC analysis.

\subsection{Instrumental and Analytical Conditions}

The RP-HPLC method used in this work was modified from a previous report (Rangkadilok, et al., 2010). The analysis of standards and test samples were performed using the external standard method on a Waters 1525 high-performance liquid chromatography system with a Waters 2996 UV/Vis detector (Waters Corporation, Milford, MA, USA). A Waters Bridge ${ }^{\circledR}$ C18 reversed-phase analytical column $(4.6 \times 250 \mathrm{~mm}, 5 \mu \mathrm{m})$ was used in this study. The mobile phase consisted of methanol (solvent A) and water (solvent B) using the following gradient method: 0 min, $5 \%$ A; 0-5 min, 5-18\% A; 5-10 min, $18-35 \%$ A; $10-15$ min, 35-62\% A; 15-30 min, 62-83\% A, 30-31 min, 83-98\% A; 31-50 min, 98\% A; 50-51 min, 98-5\% A; and equilibrated at $5 \% \mathrm{~A}$ for $3 \mathrm{~min}$. The run time for each sample was 54 minutes. The flow rate was $1.0 \mathrm{~mL} \mathrm{~min}{ }^{-1}$ with UV absorption wavelength at $295 \mathrm{~nm}$. The column compartment temperature was maintained at $25{ }^{\circ} \mathrm{C}$ and the injection volume was $20 \mu \mathrm{L}$.

\subsection{Method Validation}

To confirm the reliability of the method, accuracy, precision, limit of quantification (LOQ), limit of detection (LOD), linearity, and linear range of the method were verified. As the retention time of each compound is characteristic for specific chromatographic conditions (mobile phase composition, chromatographic column, column temperature, etc.), the retention times for the qualitative analysis of the six standards were determined by individual injection. The external standard method was used for the quantitative analysis of analytes. Calibration curves were prepared using a series of the working standard solutions. The peak areas corresponding to each of the standards in a mixture were determined at varying concentrations and standard curves were drawn. The concentration of the sample was determined from the standard curve corresponding to the peak area. The accuracy of the method is expressed as recoveries, and the precision is expressed as the relative standard deviation (RSD) calculated from the peak areas of six samples prepared in parallel from the same sample. The LOQ, LOD, linearity, and linear range of the method were collected, recorded and processed using Waters Empower software.

\subsection{Data Analysis}

The analysis of variance (ANOVA) and significant differences were calculated using SPSS 18.0 statistical software. Sample preparation and analyses were performed in triplicate, and the results were expressed as mean \pm standard deviation $(\mathrm{x} \pm \mathrm{SD})$. The Waters Empower software was used to assess the chromatographic peaks and manual corrections were performed as needed. Data analysis and plotting were performed using Origin 9.0.

\section{Results and Discussion}

\subsection{Method Validation}

The lignans and tocopherols in sesame oil were simultaneously separated by $\mathrm{C} 18$ reversed-phase analytical column. The six analytes were well-resolved (resolution $>1.5$ ) by gradient elution using a methanol-water solution as the mobile phase. The retention times of sesamol, sesamin, sesamolin, $\delta_{-}^{-}, \gamma^{-}$, and $\alpha$-tocopherol were $16.17,22.83,24.09,41.63,42.99$, and $44.53 \mathrm{~min}$, respectively. Chromatograms of the six analytes in one standard solution (a) and a sesame oil sample (b) are shown in Fig. 2. 
A series of standard solutions, composed of six analytes at seven different concentrations, were used to prepare calibration curves with the standard solution concentration $\left(\mu \mathrm{g} \mathrm{mL} \mathrm{L}^{-1}\right)$ as the abscissa and the area of absorption peak determined by HPLC as the ordinate. The regression equations and coefficients of correlation $\left(\mathrm{R}^{2}\right)$ obtained from the calibration curves of the six analytes using the chromatographic conditions described (seeSection 2.3) are shown in Table 1. The correlation coefficients obtained for each analyte $\left(\mathrm{R}^{2}=0.9997\right.$ 1.0000) showed that this method is reliable for analysis of samples with a wide range of concentrations: 1.00-500.0 $\mu \mathrm{g} \mathrm{mL}-1$ for sesamol, $0.50-650.0 \mu \mathrm{g} \mathrm{mL}^{-1}$ for sesamin, $0.50-600.0 \mu \mathrm{g} \mathrm{mL} \mathrm{m}^{-1}$ for sesamolin, $0.50-200.0$ $\mu \mathrm{g} \mathrm{mL} \mathrm{mL}^{-1}$ for $\alpha$-tocopherol, 1.00-300.0 $\mu \mathrm{g} \mathrm{mL} \mathrm{m}^{-1}$ for $\gamma$-tocopherol, and $0.50-200.0 \mu \mathrm{g} \mathrm{mL} \mathrm{m}^{-1}$ for $\delta$-tocopherol. Empower software was used to calculate the signal-to-noise ratio for the lignans and tocopherols. These values were used to determine LODs and LOQs, where LOD is the corresponding concentration when the signal-to-noise $=3: 1$, and LOQ is the corresponding concentration when the signal-to-noise $=10: 1$. The LODs and LOQs of the lignans and tocopherols were in the range of 0.1-0.3 and 0.3-1.0 $\mu \mathrm{gL}^{-1}$, respectively (Table 1).

Sesame oil samples with known lignan and tocopherol content were selected for spike-in recovery experiments. Lignan and tocopherol standards were added at high $\left(5000 \mu \mathrm{g} \mathrm{g}^{-1}\right)$, medium $\left(500 \mu \mathrm{g} \mathrm{g}^{-1}\right)$, and low $\left(50 \mu \mathrm{g} \mathrm{g}^{-1}\right)$ concentrations, and the resultant samples were analyzed by RP-HPLC. The average recovery and relative standard deviation (RSD) were calculated for six replicates of each spike-in concentration (Table 2). The average recoveries of the spike-in samples ranged from $88.22 \%$ to $100.13 \%$, and the RSD $(n=6)$ ranged from $1.90 \%$ to $4.57 \%$. These results show that the method established in this paper has excellent accuracy and precision.

In general, this method benefits from (1) a small volume of organic solvent for sample pretreatment (10 mL), (2) rapid preparation (27 min), (3) a simple experimental procedure, (4) high resolution, and (5) sufficient accuracy and precision to meet detection requirements. This method is therefore suitable for routine analysis.

\subsection{Determination of lignans and tocopherols in sesame oil samples}

A chromatogram of a sesame oil sample shows no interference peak near the tested analytes (Fig. 2 (b)), indicating that the method has good selectivity. Different brands of sesame oil prepared via various processing methods were analyzed using the method established in this work (Table 3). Concentrations of sesamol, sesamin, sesamolin, and total lignans in the tested sesame oils were ND-339.1, 3640.1-6118.9, 2525.6-3616.0, and 6529.3-9891.7 $\mu \mathrm{g} \mathrm{g}^{-1}$, respectively. Sesamin and sesamolin are the primary lignans in sesame oil, and there were significant differences in the content of sesamin in different sesame oils $(\mathrm{p}<0.05)$. The roasted sesame oils (hot-pressed sesame oil samples 1,2; grinding sesame oil samples 3,4) showed significantly higher sesamol concentrations than the cold-pressed sesame oils (samples 5,6). This is because the sesamol in sesame oil is mainly derived from the thermal decomposition of sesamolin at the high temperatures in the roasting process of sesame raw materials. Therefore, the concentration of sesamol in the roasted sesame oils is high (171.7-339.1 $\mu \mathrm{g} \mathrm{g}^{-1}$ ) and that in the cold-pressed sesame oil is very low (ND-12.2 $\mu \mathrm{g} \mathrm{g}^{-1}$ ), which is consistent with the results observed by Shi et al. (2017). In addition, the concentration of sesamin in the roasted sesame oil is higher than that in the cold-pressed sesame oil. This could arise due to the increased oil yield from the roasting process, which could serve to extract more sesamin, despite its unequal distribution in sesame. Furthermore, sesamin is relatively stable during baking and is therefore maintained in high yield during roasting.

The contents of $\alpha$-tocopherol, $\gamma$-tocopherol, $\delta$-tocopherol, and total tocopherols in sesame oil obtained by different processing technologies were ND-9.8, 428.4-529.7, ND-14.4, and 452.6-546.4 $\mu \mathrm{g} \mathrm{g}^{-1}$, respectively. The most concentrated tocopherol in sesame oil was $\gamma$-tocopherol. The concentrations of $\alpha$-tocopherol and $\delta$-tocopherol were less than $15.0 \mu \mathrm{g} \mathrm{g}^{-1}$. In fact, $\delta$-tocopherol and $\alpha$-tocopherol were not detected in samples 3 and 5 , respectively. There was no significant difference $(\mathrm{p}>0.05)$ in total tocopherol contents between cold-pressed and roasted sesame oils.

\section{Conclusions}

An RP-HPLC method for the simultaneous detection of lignans (sesamol, sesamin, sesamolin) and toco- 
pherols ( $\alpha$-tocopherol, $\gamma$-tocopherol, $\delta$-tocopherol) in sesame oil was established and verified. The LODs and LOQs of the six analytes were 0.1-0.3 and 0.3-1.0 $\mu \mathrm{g} \mathrm{mL}-1$, respectively. The recoveries of the samples were 88.22-100.13\%, and the relative standard deviations (RSD, $\mathrm{n}=6$ ) were $1.90-4.57 \%$.

Six sesame oil samples were tested using the method established in this paper. The results showed that the main tocopherol in sesame oil was $\gamma$-type, and the contents of sesamin and sesamolin were higher than sesamol. The contents of total lignan and total tocopherol were 6529.3-9891.7 and 452.6-546.4 $\mu \mathrm{g} \mathrm{g}^{-1}$, respectively. Featuring simple operation, effective separation, and accurate results, this method is ideal for the routine analysis of antioxidant contents (lignans and tocopherols) in sesame oil.

\section{Acknowledgments}

This research was financially supported by the National Natural Science Foundation of China (No. 31371729 and No. 31801504) and the Fundamental Research Funds for the Central Universities of China (Grant No. PA2019GDPK0065).

\section{References}

Ballus, C. A., Meinhart, A. D., Campos, F. A. D. S., Silva, L. F. d. O. d., \& Godoy, H. T. (2014). A quantitative study on the phenolic compound, tocopherol and fatty acid contents of monovarietal virgin olive oils produced in the southeast region of Brazil. Food Research International, 62 , 74-83.

Barve, A., Khor, T. O., Nair, S., Reuhl, K., \& Kong, A. N. (2009). Gamma-tocopherol-enriched mixed tocopherol diet inhibits prostate carcinogenesis in TRAMP mice. International Journal of Cancer,124, 1693-1699.

Duggan, S., O'Sullivan, M., Feehan, S., Ridgway, P., \& Conlon, K. (2010). Nutrition Treatment of Deficiency and Malnutrition in Chronic Pancreatitis: A Review. Nutrition in Clinical Practice,25 , 362-370.

Fernandes, L., Pereira, J. A., Lopéz-Cortés, I., Salazar, D. M., Ramalhosa, E., \& Casal, S. (2015). Fatty acid, vitamin E and sterols composition of seed oils from nine different pomegranate (Punica granatum L.) cultivars grown in Spain. Journal of Food Composition \&3 Analysis, 39 , 13-22.

Ghafoorunissa, Hemalatha, S., \& Rao, M. V. V. (2004). Sesame lignans enhance antioxidant activity of vitamin E in lipid peroxidation systems.Molecular \& Cellular Biochemistry, 262, 195-202.

Helzlsouer, K. J., Huang, H. Y., Alberg, A. J., Hoffman, S., Burke, A., Norkus, E. P., Morris, J. S., \& Comstock, G. W. (2018). Association Between $\alpha$-Tocopherol, $\gamma$-Tocopherol, Selenium, and Subsequent Prostate Cancer. Journal of the National Cancer Institute, 92, 2018-2023.

Hemalatha, S., \& Ghafoorunissa. (2004). Lignans and tocopherols in Indian sesame cultivars. Journal of the American Oil Chemists'Society, 81 , 467-470.

Hirata, F., Fujita, K., Ishikura, Y., Hosoda, K., Ishikawa, T., \& Nakamura, H. (1996). Hypocholesterolemic effect of sesame lignan in humans. Atherosclerosis, 122, 135-136.

Kamal-Eldin, A., Appelqvist, L. A., \& Yousif, G. (1994). Lignan analysis in seed oils from fourSesamum species: Comparison of different chromatographic methods. Journal of the American Oil Chemists' Society, $\mathbf{7 1}, 141-147$.

Kamal-Eldin, A., Yousif, G., \& Appelqvist, L. Å. (1991). Thin-layer chromatographic separations of seed oil unsaponifiables from four Sesamum species. Journal of the American Oil Chemists Society,68 , 844-847.

Konsoula, Z., \& Liakopouloukyriakides, M. (2010). Effect of endogenous antioxidants of sesame seeds and sesame oil to the thermal stability of edible vegetable oils. LWT - Food Science and Technology,43 , 13791386.

Li, Y., Ye, M., Liu, H., Ji, X., \& Yan, Y. (2002). Characterization and analysis of Semen Cuscutae by capillary 
gas chromatography and gas chromatography-mass spectrometry. Journal of Separation Science,25 , 255259.

Longnecker, M. P., Martin-Moreno, J. M., Knekt, P., Nomura, A. M. Y., Schober, S. E., Stähelin, H. B., Wald, N. J., Gey, K. F., \& Willett, W. C. (1992). Serum alpha-tocopherol concentration in relation to subsequent colorectal cancer: pooled data from five cohorts. Journal of the National Cancer Institute, $\mathbf{8 4}$, $430-435$.

Mahendra Kumar, C., \& Singh, S. A. (2015). Bioactive lignans from sesame (Sesamum indicum L.): evaluation of their antioxidant and antibacterial effects for food applications. Journal of Food Science 85 Technology, 52, 2934-2941.

Morel, S., Didierlaurent, A., Bourguignon, P., Delhaye, S., Baras, B., Jacob, V., Planty, C., Elouahabi, A., Harvengt, P., \& Carlsen, H. (2011). Adjuvant System AS03 containing $\alpha$-tocopherol modulates innate immune response and leads to improved adaptive immunity. Vaccine,29 , 2461-2473.

Namiki, \& Mitsuo. (1995). The chemistry and physiological functions of sesame. Food Reviews International, 11, 281-329.

Pruthi, S., Allison, T. G., \& Hensrud, D. D. (2001). Vitamin E Supplementation in the Prevention of Coronary Heart Disease. Mayo Clinic Proceedings, 76 , 1131-1136.

Rangkadilok, N., Pholphana, N., Mahidol, C., Wongyai, W., Saengsooksree, K., Nookabkaew, S., \& Satayavivad, J. (2010). Variation of sesamin, sesamolin and tocopherols in sesame (Sesamum indicum L.) seeds and oil products in Thailand. Food Chemistry, 122, 724-730.

Shi, L. K., Liu, R. J., Jin, Q. Z., \& Wang, X. G. (2017). The Contents of Lignans in Sesame Seeds and Commercial Sesame Oils of China. Journal of the American Oil Chemists Society, 94, 1035-1044.

Shi, L. K., Zheng, L., Xiang, Y. F., Liu, R. J., Chang, M., Jin, Q. Z., \& Wang, X. G. (2018). A Rapid Method for Simultaneous Analysis of Lignan and $\gamma$-Tocopherol in Sesame Oil by Using Normal-Phase Liquid Chromatography. Journal of the American Oil Chemists' Society,95 , 13-19.

Smolarek, A. K., \& Nanjoo, Suh. (2011). Chemopreventive Activity of Vitamin E in Breast Cancer: A Focus on $\gamma$ - and $\delta$-Tocopherol.Nutrients, $\mathbf{3}, 962-986$.

Suja, K. P., Jayalekshmy, A., \& Arumughan, C. (2004). Free Radical Scavenging Behavior of Antioxidant Compounds of Sesame (Sesamum indicum L.) in DPPH¥ System. Journal of Agricultural \& Food Chemistry,52, 912-915.

Tashiro, T., Fukuda, Y., Osawa, T., \& Namiki, M. (1990). Oil and minor components of sesame (Sesamum indicum L.) strains. Journal of the American Oil Chemists' Society, 67 , 508-511.

Utsunomiya, T. (2000). Effects of sesamin-supplemented dietary fat emulsions on the ex vivo production of lipopolysaccharide-induced prostanoids and tumor necrosis factor alpha in rats. American Journal of Clinical Nutrition, 72 , 804-808.

Visavadiya, N. P., \& Narasimhacharya, A. V. R. L. (2008). Sesame as a hypocholesteraemic and antioxidant dietary component. Food \& Chemical Toxicology, 46 , 1889-1895.

Wan, Y., Li, H., Fu, G., Chen, X., Chen, F., \& Xie, M. (2015). The relationship of antioxidant components and antioxidant activity of sesame seed oil. Journal of the Science of Food 83 Agriculture,95 , 2571-2578.

Williamson, K. S., Morris, J. B., Pye, Q. N., Kamat, C. D., \& Hensley, K. (2008). A survey of sesamin and composition of tocopherol variability from seeds of eleven diverse sesame ( Sesamum indicum L.) genotypes using HPLC-PAD-ECD. Phytochemical Analysis,19 , 311-322.

$\mathrm{Wu}, \mathrm{W}$. H. (2007). The contents of lignans in commercial sesame oils of Taiwan and their changes during heating. Food Chemistry,104, 341-344. 
Xu, T., Yang, R., Hua, X., Zhao, W., \& Zhang, W. (2018). Improvement of the yield and flavour quality of sesame oil from aqueous extraction process by moisture conditioning before roasting. International Journal of Food Science \&3 Technology, 54, 471-479.

Yashaswini, P. S., Rao, A. G. A., \& Singh, S. A. (2016). Inhibition of lipoxygenase by sesamol corroborates its potential anti-inflammatory activity. International Journal of Biological Macromolecules,94 , 781-787.

Yokota, T., Matsuzaki, Y., Koyama, M., HitomiT., Kawanaka, M., Enoki-Konishi, M., Okuyama, Y., Takayasu, J., Nishino, H., \& Nishikawa, A. (2007). Sesamin, a lignan of sesame, down-regulates cyclin D1 protein expression in human tumor cells. Cancer Science, 98, 1447-1453.

Table captions

Table 1 Regression equations, correlation coefficients $\left(\mathrm{R}^{2}\right)$, LOQs, LODs, and concentration ranges of lignans and tocopherols

Table 2 Recoveries and RSDs of lignans and tocopherols in sesame oil samples

Table 3 Lignan and tocopherol concentrations in sesame oil samples $\left(\mu \mathrm{g} \mathrm{g} \mathrm{g}^{-1}\right)$

Figure captions

Fig. 1 Structures of $\alpha-, \gamma$-, $\delta$-tocopherols, sesamol, sesamolin, and sesamin

Fig. 2 RP-HPLC chromatograms of a mixture of lignan and tocopherol standards (a) and a methanol extract of sesame oil (b)

Table 1 Regression equations, correlation coefficients $\left(\mathrm{R}^{2}\right)$, LOQs, LODs, and concentration ranges of lignans and tocopherols

\begin{tabular}{|c|c|c|c|c|c|}
\hline Analyte & $\begin{array}{l}\text { Regression } \\
\text { equation }\end{array}$ & $\begin{array}{l}\text { Linear } \\
\text { regression } \\
\text { coefficient } \\
\left(\mathbf{R}^{2}\right)\end{array}$ & $\begin{array}{l}\text { LOD }(\mu \gamma \\
\left.\mu \Lambda^{-1}\right)\end{array}$ & $\begin{array}{l}\text { LOQ }(\mu \gamma \\
\left.\mu \Lambda^{-1}\right)\end{array}$ & 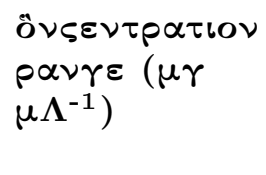 \\
\hline Sesamol & $\begin{array}{l}y=28,131 x- \\
101,334\end{array}$ & 0.9997 & 0.3 & 1.0 & $1.00-500.0$ \\
\hline Sesamin & $\begin{array}{l}y=25,841 \mathrm{x}+ \\
14,565\end{array}$ & 1.0000 & 0.1 & 0.3 & $0.50-650.0$ \\
\hline Sesamolin & $\begin{array}{l}\mathrm{y}=16,579 \mathrm{x}+ \\
4,364\end{array}$ & 0.9999 & 0.15 & 0.5 & $0.50-600.0$ \\
\hline$\alpha$-Tocopherol & $\begin{array}{l}y=5,296 x- \\
17,475\end{array}$ & 0.9998 & 0.1 & 0.3 & $0.50-200.0$ \\
\hline$\gamma$-Tocopherol & $\begin{array}{l}y=6,773 x- \\
22,684\end{array}$ & 1.0000 & 0.15 & 0.5 & $1.00-300.0$ \\
\hline$\delta$-Tocopherol & $\begin{array}{l}y=7,786 x- \\
17,278\end{array}$ & 0.9999 & 0.1 & 0.3 & $0.50-200.0$ \\
\hline
\end{tabular}

Table 2 Recoveries and RSDs of lignans and tocopherols in sesame oil samples

\begin{tabular}{|c|c|c|c|}
\hline Analyte & 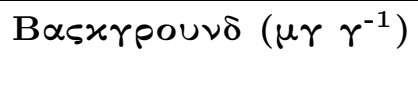 & 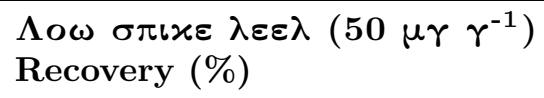 & 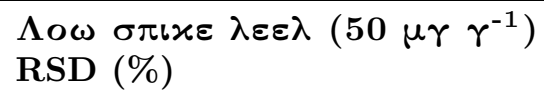 \\
\hline Sesamol & 195.6 & 88.22 & $4.57-120$ \\
\hline Sesamin & 5364.6 & 93.57 & 3.28 \\
\hline Sesamolin & 2525.6 & 91.46 & 3.96 \\
\hline$\alpha$-Tocopherol & 9.8 & 89.08 & 3.41 \\
\hline$\gamma$-Tocopherol & 428.4 & 95.97 & 2.63 \\
\hline
\end{tabular}


Table 3 Lignan and tocopherol concentrations in sesame oil samples ( $\left.\mu g \mathrm{~g}^{-1}\right)$

\begin{tabular}{|c|c|c|c|c|c|}
\hline Analyte & $\begin{array}{l}\text { Mean } \pm \operatorname{SD}(n=3) \\
1\end{array}$ & $\begin{array}{l}\text { Mean } \pm \operatorname{SD}(n=3) \\
2\end{array}$ & $\begin{array}{l}\text { Mean } \pm \operatorname{SD}(n=3) \\
3\end{array}$ & $\begin{array}{l}\text { Mean } \pm \operatorname{SD}(n=3) \\
4\end{array}$ & $\begin{array}{l}\text { Mean } \pm \\
5\end{array}$ \\
\hline Sesamol & $195.6 \pm 4.53^{\mathrm{b}}$ & $212.3 \pm 8.59^{\mathrm{b}}$ & $171.7 \pm 7.26^{\mathrm{c}}$ & $339.1 \pm 11.55^{\mathrm{a}}$ & $\mathrm{ND}^{\mathrm{d}}$ \\
\hline Sesamin & $5364.6 \pm 119.58^{\mathrm{b}}$ & $5158.6 \pm 81.46^{\mathrm{b}}$ & $5356.2 \pm 65.66^{\mathrm{b}}$ & $6118.9 \pm 116.02^{\mathrm{a}}$ & $3640.1 \pm$ \\
\hline Sesamolin & $2525.6 \pm 134.03^{\mathrm{d}}$ & $2812.5 \pm 54.05^{\mathrm{c}}$ & $3100.7 \pm 77.19^{\mathrm{b}}$ & $3433.7 \pm 60.66^{\mathrm{a}}$ & $2889.2=$ \\
\hline Total lignans & $8085.8 \pm 256.43^{\mathrm{c}}$ & $8183.4 \pm 41.48^{\mathrm{bc}}$ & $8628.6 \pm 149.34^{\mathrm{b}}$ & $9891.7 \pm 187.31^{\mathrm{a}}$ & $6529.3 \pm$ \\
\hline$\alpha$-Tocopherol & $9.8 \pm 0.16^{\mathrm{a}}$ & $9.3 \pm 0.14^{\mathrm{a}}$ & $7.9 \pm 0.18^{\mathrm{c}}$ & $8.4 \pm 0.22^{\mathrm{b}}$ & $\mathrm{ND}^{\mathrm{d}}$ \\
\hline$\gamma$-Tocopherol & $428.4 \pm 15.03^{\mathrm{b}}$ & $472.4 \pm 11.22^{\mathrm{ab}}$ & $518.9 \pm 12.78^{\mathrm{a}}$ & $529.7 \pm 39.24^{\mathrm{a}}$ & $491.8 \pm 7$ \\
\hline ס-Tocopherol & $14.4 \pm 0.30^{\mathrm{a}}$ & $12.0 \pm 0.19^{\mathrm{b}}$ & $\mathrm{ND}^{\mathrm{e}}$ & $8.2 \pm 0.18^{\mathrm{d}}$ & $11.3 \pm 0$ \\
\hline Total tocopherols & $452.6 \pm 14.91^{\mathrm{b}}$ & $493.7 \pm 11.55^{\mathrm{ab}}$ & $526.8 \pm 12.62^{\mathrm{a}}$ & $546.4 \pm 39.60^{\mathrm{a}}$ & $503.1 \pm 7$ \\
\hline
\end{tabular}

Values in the same row with different superscript letters are significantly different at $\mathrm{P}<0.05$.

$\mathrm{ND}=$ not detectable.

Fig. 1 Structures of $\alpha-, \gamma-, \delta$-tocopherols, sesamol, sesamolin, and sesamin<smiles>CCCCC1(C)CCc2c(C)c(O)c(C)c(C)c2O1</smiles><smiles>CCCCC1(C)CCc2cc(O)c(C)c(C)c2O1</smiles><smiles>CCCCC1(C)CCc2cc(O)cc(C)c2O1</smiles><smiles>Oc1ccc2c(c1)OCO2</smiles>
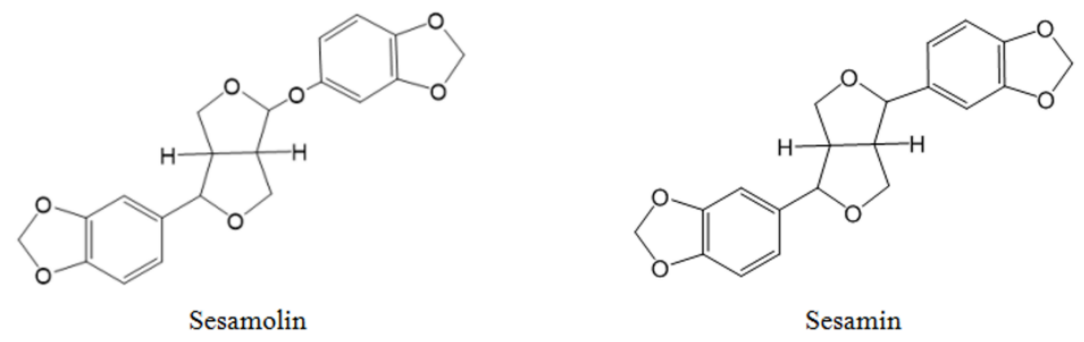

Fig. 2 RP-HPLC chromatograms of a mixture of lignan and tocopherol standards (a) and a methanol extract of sesame oil (b) 


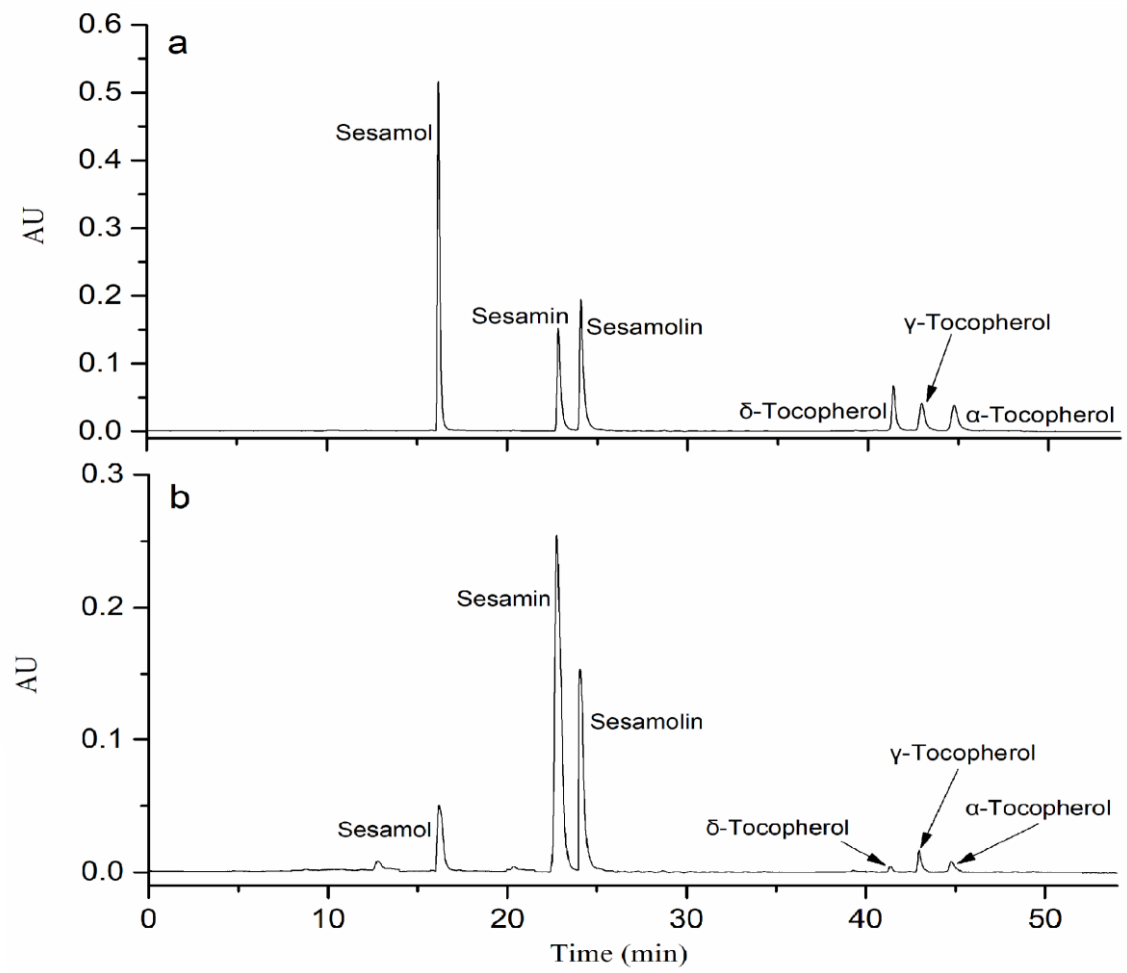

